\title{
Effect of Milling Time on Surface Morphology of AISI 01
}

\author{
Kelvii Wei Guo* \\ Department of Mechanical and Biomedical Engineering, City University of Hong Kong, 83 Tat Chee Avenue, Kowloon Tong, \\ Kowloon, Hong Kong
}

\begin{abstract}
AISI 01 was processed by surface milling and the influence of milling time on the surface morphology was studied by 3D profilometer and scanning electron microscopy (SEM). Results show that when AISI 01 specimens are processed with various milling time, the morphology of AISI O1 changes correspondingly. Moreover, it demonstrates that the initial increase in milling time accompanies with the increase in surface roughness until the milling time reaches $60 \mathrm{~min}$ at which the surface roughness is the minimum.
\end{abstract}

Received on 15-11-2017 Accepted on 15-12-2017 Published on 10-01-2018

Keywords: Milling, surface morphology, roughness, AISI 01.

\section{INTRODUCTION}

Conventionally, the surface finishing of metal molds is always done by hand lapping after milling and/or electrical discharge machining in order to attain small surface roughness without micro cracks. However, in this process operator shortcomings cause these manual processing methods to have a number of limitations. Meanwhile, consistency and repeatability are also required. Consequently, the process is extremely timeconsuming, which leads to high cost [1].

Whilst automated processes, suitable for the finishing of closed dies, they are limited in their application. For example, precision machining using a single point diamond tool is slow, requires conditions not readily available in an industrial environment and is limited to flat surfaces [2-4]. Chemical micromachining and electrochemical micromachining are limited in their application and can be difficult to control [4-6].

Laser has also been widely used as a machine tool to modify the surface of the engineering materials, such as laser surface alloying, laser cladding, surface texturing, laser physical vapor deposition, laser polishing, etc [2, 7-12].

Ultimately, surface modifications or surface treatments are vitally taken for increasing service life of the critical components and devices used for engineering and structural

"Department of Mechanical and Biomedical Engineering, City University of Hong Kong, 83 Tat Chee Avenue, Kowloon Tong, Kowloon, Hong Kong; E-mail: kelviiguo@yahoo.com functions. Numerous surface engineering approaches just as the above mentioned such as thermal, chemical, mechanical, as well as hybrid treatments are employed to improve or vary/change the surface finish.

In this work, an attempt has been made to vary the morphology of AISI $\mathrm{O} 1$ by surface milling. The morphology of the initial surface was studied. After processed, the influence of milling time on the surface morphology of AISI 01 was studied by 3D profilometer and scanning electron microscope (SEM).

\section{EXPERIMENTAL MATERIAL AND PROCEDURES}

\subsection{Experimental Material}

The chemical composition of AISI O1 tool steel is shown as Table 1.

Table 1: Chemical Composition of AISI 01 Tool Steel

\begin{tabular}{|c|c|c|c|c|c|c|c|}
\hline Element & C & Si & Mn & Cr & W & V & Fe \\
\hline \hline (wt.\%) & 0.9 & 0.3 & 1.2 & 0.5 & 0.5 & 0.1 & Bal. \\
\hline
\end{tabular}

\subsection{Experimental Procedures}

The materials were machined into $25 \mathrm{~mm} \times 25 \mathrm{~mm} \times 5 \mathrm{~mm}$ and carefully cleaned by acetone and pure ethyl alcohol to remove any contaminants on its surface. Figure 1 shows the Talysurf 3D topography of the original AISI $\mathrm{O} 1$ tool steel 


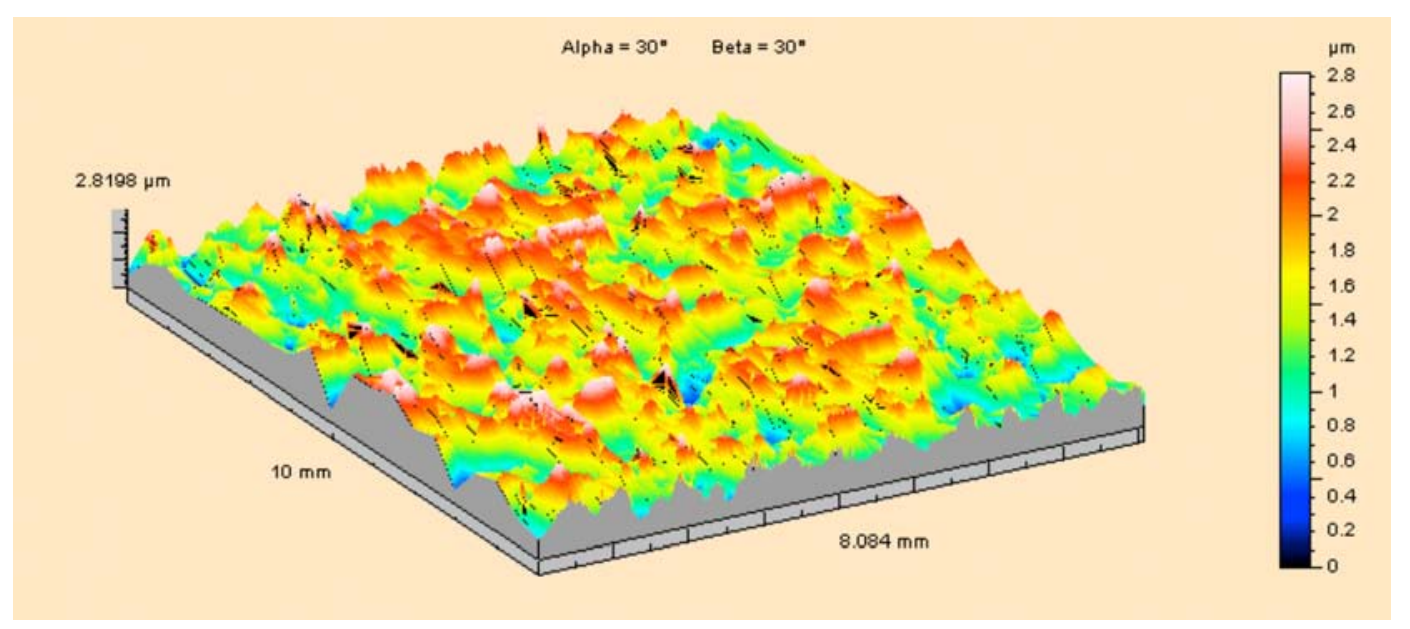

Figure 1: Topography of the original AISI O1.

specimen, whilst Figure 2 shows its corresponding 2D SEM morphology.

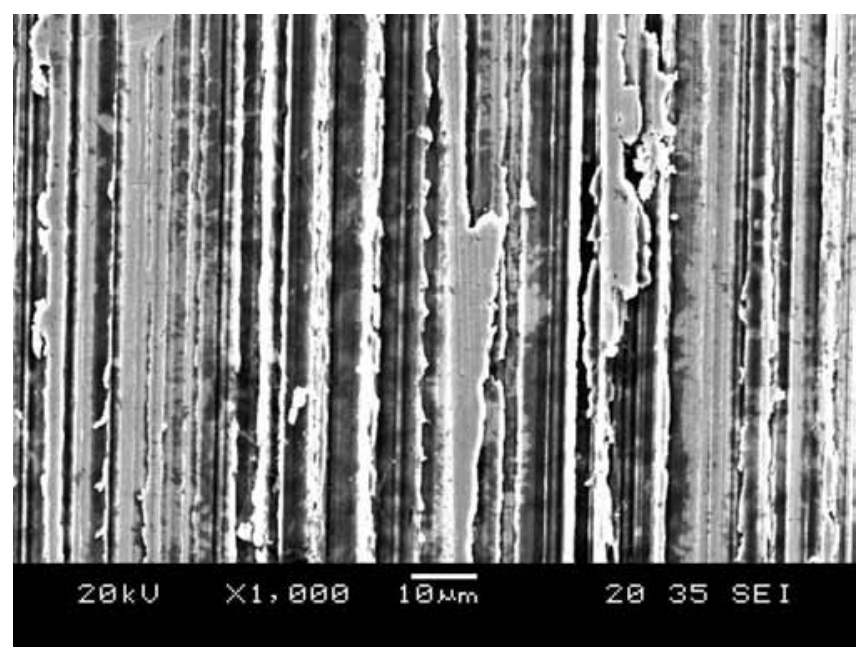

Figure 2: SEM of the initial AISI O1 surface.

The planetary mono mill "Pilverisette 6" (Made in Germany) was used for surface milling in the stainless steel milling bowl (Volume is $500 \mathrm{ml}$ ). The process was performed under the vacuum condition to prevent contaminations for $15 \mathrm{~min}, 30$ min, $60 \mathrm{~min}, 120 \mathrm{~min}$ and $180 \mathrm{~min}$ with the milling speed setting as $250 \mathrm{rpm}$, respectively. All the processed specimens were ultrasonically cleaned in an acetone bath for 10 minutes with $28 \sim 34 \mathrm{~Hz}$ frequency and carefully dried. The surface morphology of surfaces was observed by Taylor Hobson profilometer/Talysurf PGI, Optical Microscope (OM), and Scanning Electron Microscope (SEM) JEOL/JSM-5600.

\section{RESULTS AND DISCUSSION}

\subsection{Morphology of Machined Surface at Various Milling Times}

The morphology of machined surface after 15 min milling is shown in Figure $\mathbf{3}$ and its related SEM image is shown in Figure 4.
It indicates that the machined surface is smoother than its initial surface (Figures $\mathbf{1}$ and 2). According to Figures $\mathbf{3}$ and 4a, it demonstrates that there are some small ridges distributed on the machined surface. Compared Figures 3 and 4 with Figures $\mathbf{1}$ and $\mathbf{2}$, the grooves on the surface disappear, together with some smaller island-form ridges (such as labels A and B) due to the shorter milling time. The big ridges cannot be detected and the remained chippings disappear (Figure 2), resulted in the smooth machined surface shown as Figure 4a.

Moreover, the magnified parts of Figure $4 a$ are shown in Figures $4 \mathrm{~b}$ and $\mathbf{4 c}$, crack can be found on the machined surface as shown in Figure 4c (label $C$ ) as a result of effect of milling balls.

The morphology of machined surface after 30 min milling time is shown in Figure $\mathbf{5}$, and its corresponding texture is shown in Figure $\mathbf{6 a}$ and its magnification parts Figures $\mathbf{6 b}$ and 6c. Although milling balls remove most high plateaus from the original surface of the specimens (cf. Figures 2 and 6), the island-form ridges still distribute on the machined surface. As expressed in Figures $\mathbf{6 b}$ and $\mathbf{6 c}$, micropits and cracks can be observed on the surface of the substrate because the balls do not mill sufficiently.

With the increase of milling time, the machined surface becomes more and more smooth as shown in Figure 7, and the formed ridges become smaller and distribute uniformly as shown in Figure $\mathbf{8}$ where the magnifications of Figure $\mathbf{8 a}$ are shown in Figures $\mathbf{8 b}$ and $\mathbf{8 c}$. It illustrates the uniform changes of the surface topography after $60 \mathrm{~min}$ milling time. The variation of the topography of the surface machined at $60 \mathrm{~min}$ is distinct. It is observed that the AISI O1surface was machined effectively without any defects (cf. Figures 4, 6 and 8).

Generally, increase in milling time simultaneously improves the properties of the surface substrate. However, too longer milling time will be likely to destroy the surface of substrate which subsequently changes the surface topography and mechanical properties of the steel specimens. 
Journal of Coating Science and Technology, 2017, Volume 4, No. 3

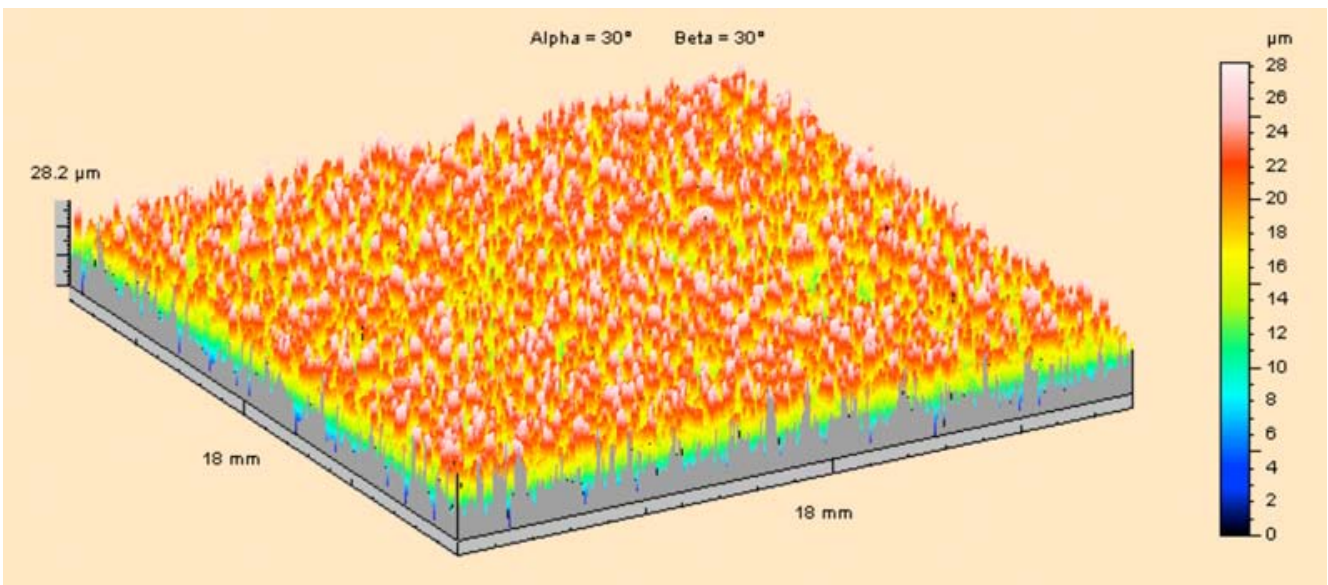

Figure 3: Morphology of machined surface after 15 min milling time.

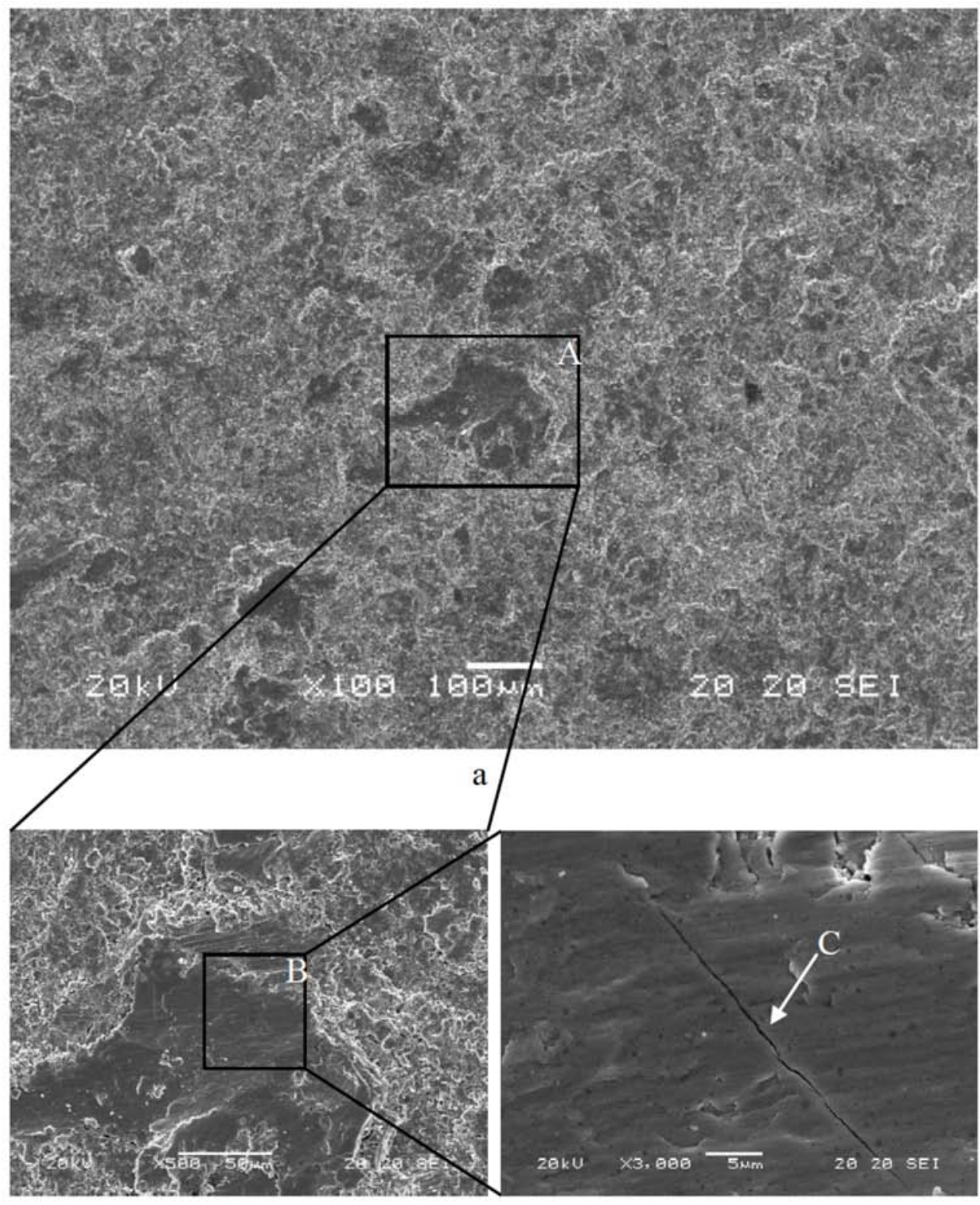

b

c

Figure 4: Machined surface after 15 min milling time. 
Journal of Coating Science and Technology, 2017, Volume 4, No. 3

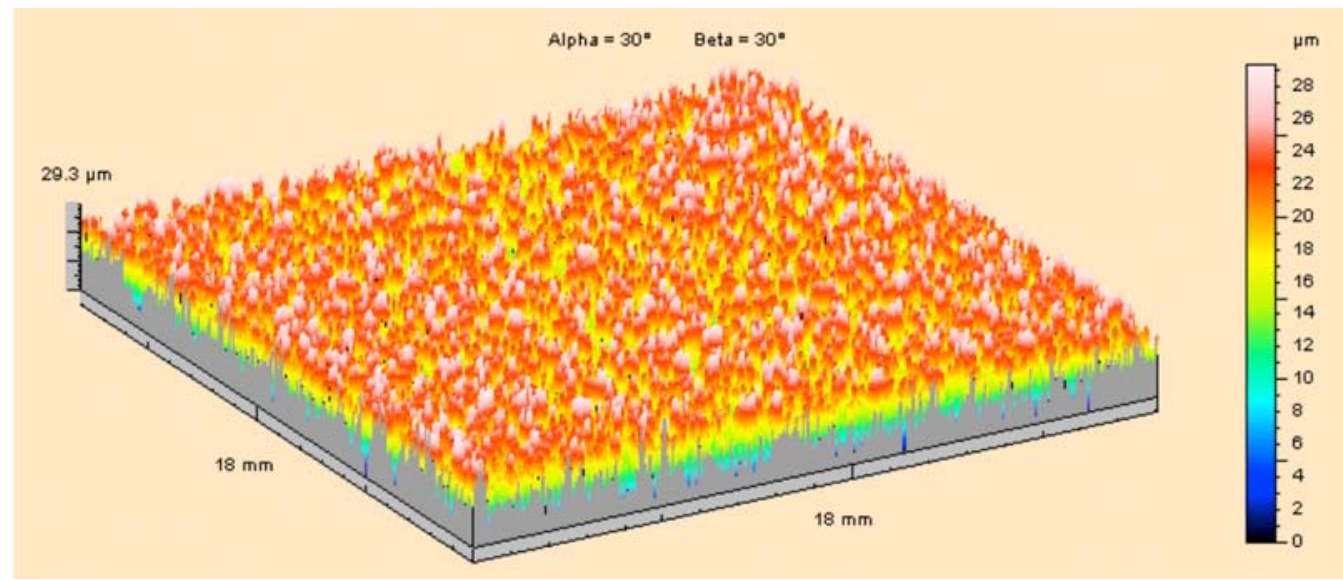

Figure 5: Morphology of machined surface after 30 min milling time.

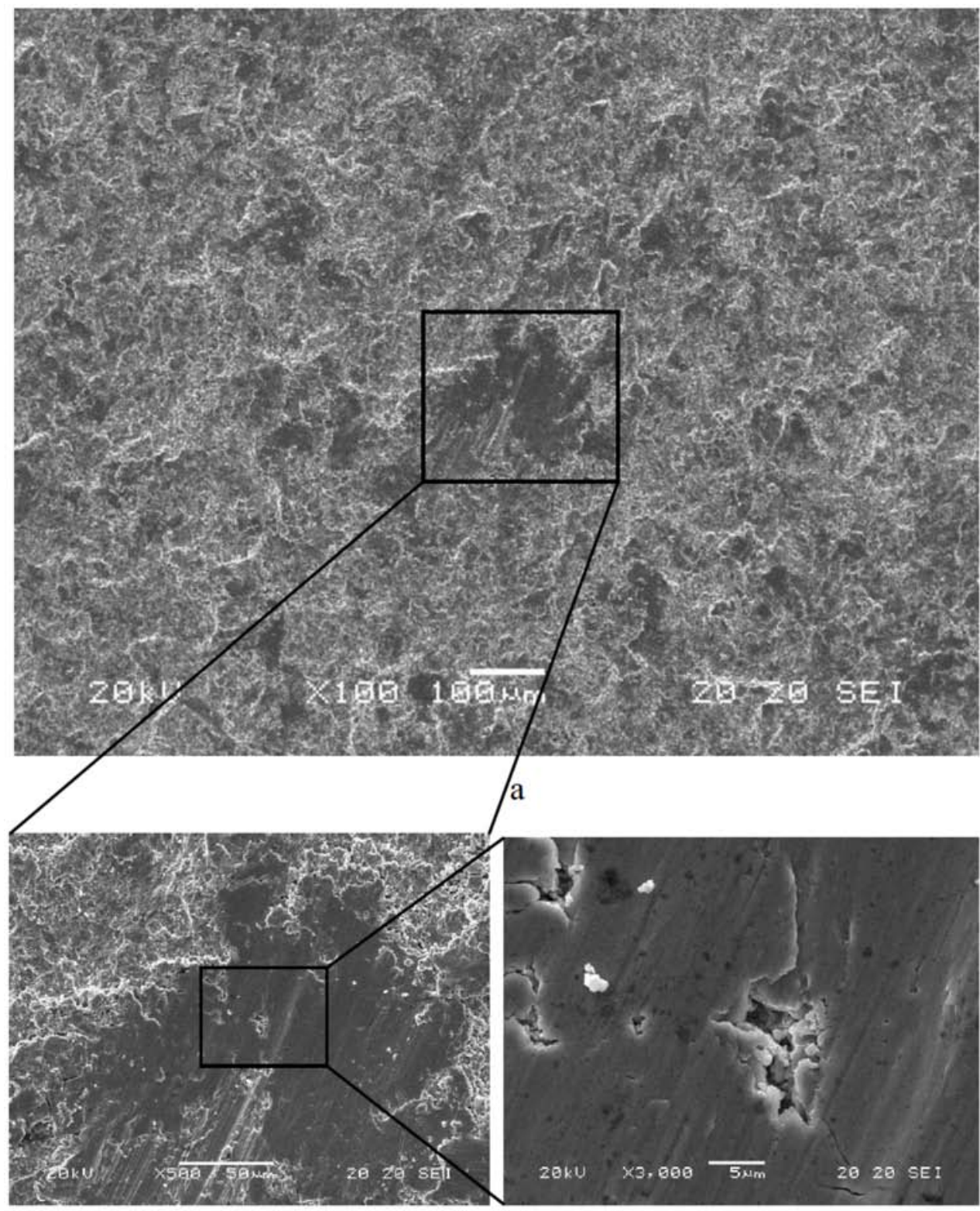

Figure 6: Machined surface after 30 min milling time. 
Journal of Coating Science and Technology, 2017, Volume 4, No. 3

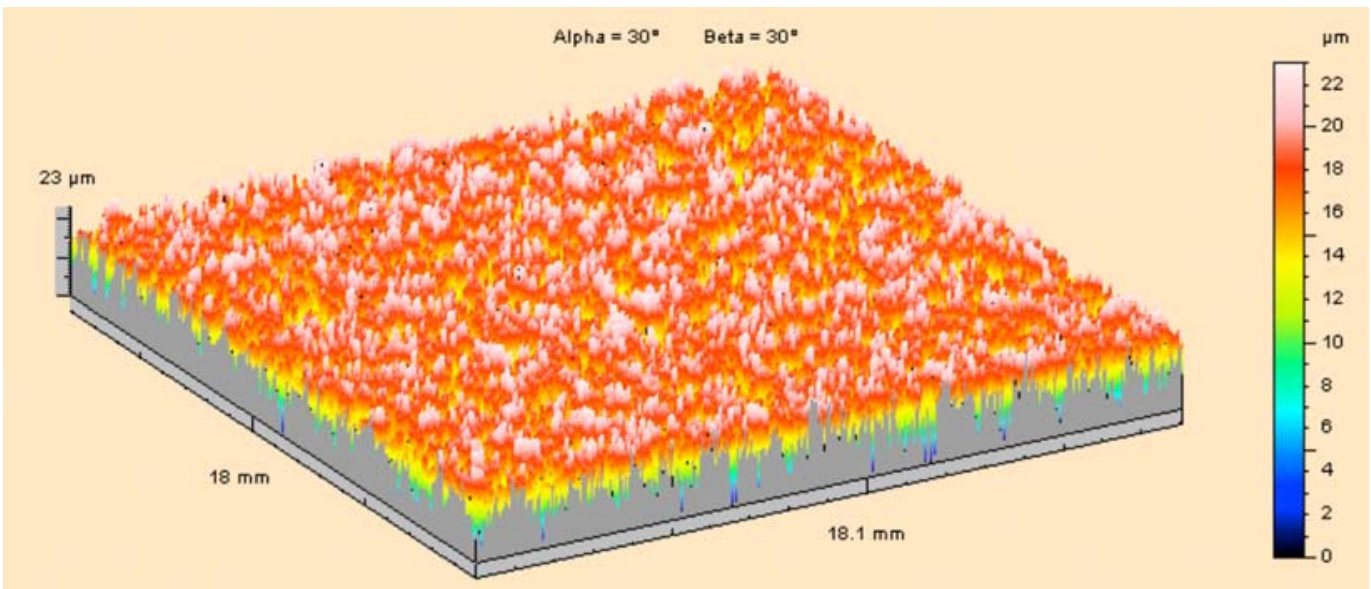

Figure 7: Morphology of machined surface after 60 min milling time.

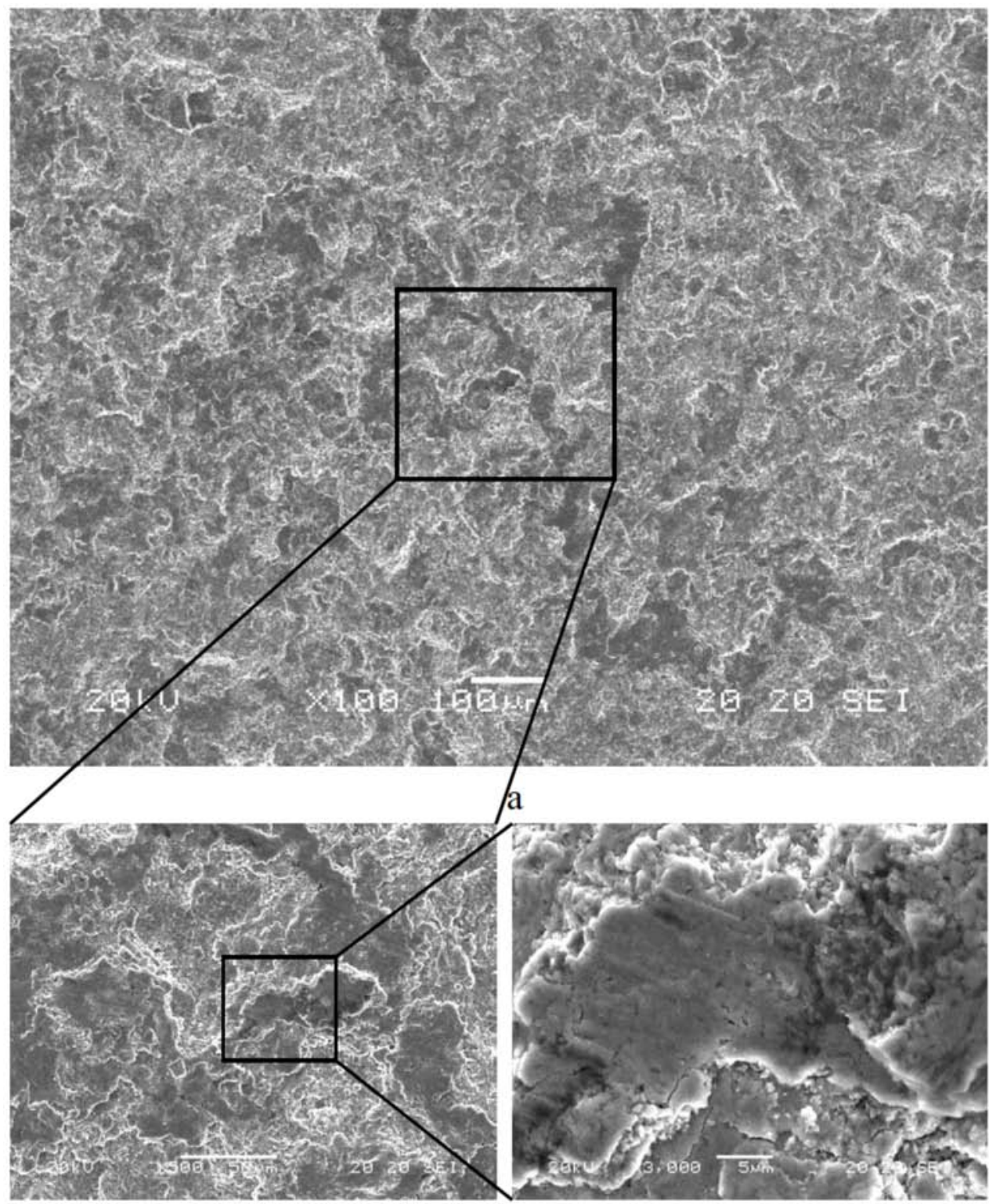

b

$\mathrm{c}$

Figure 8: Machined surface after 60 min milling time. 


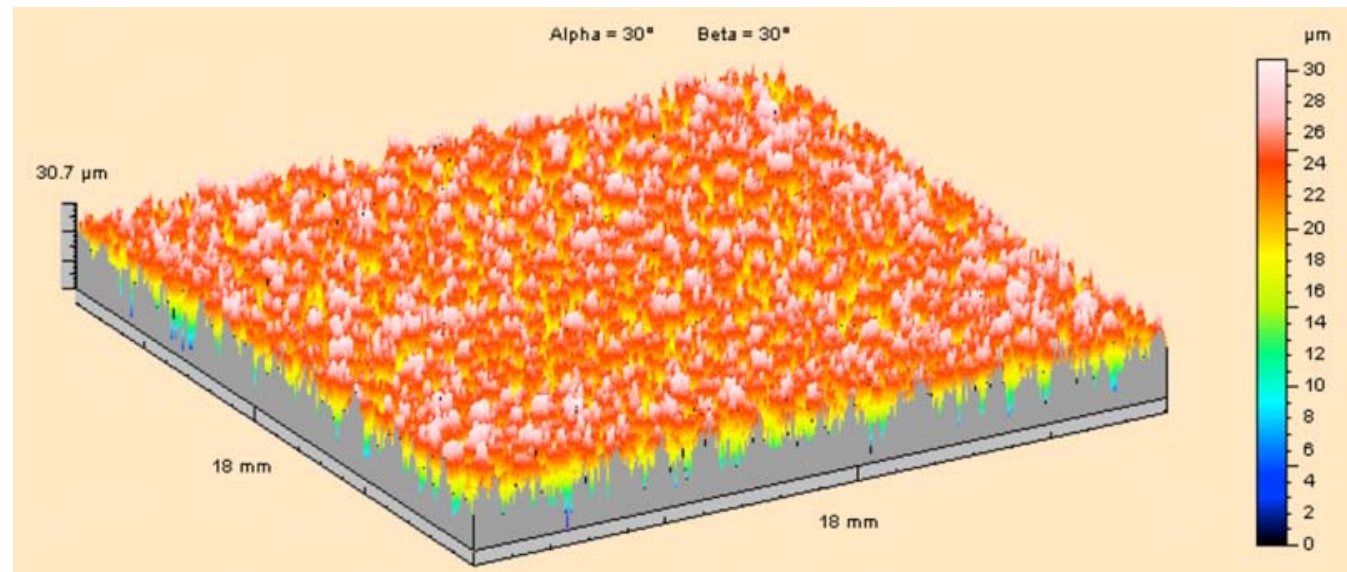

Figure 9: Morphology of machined surface after 120 min milling time.

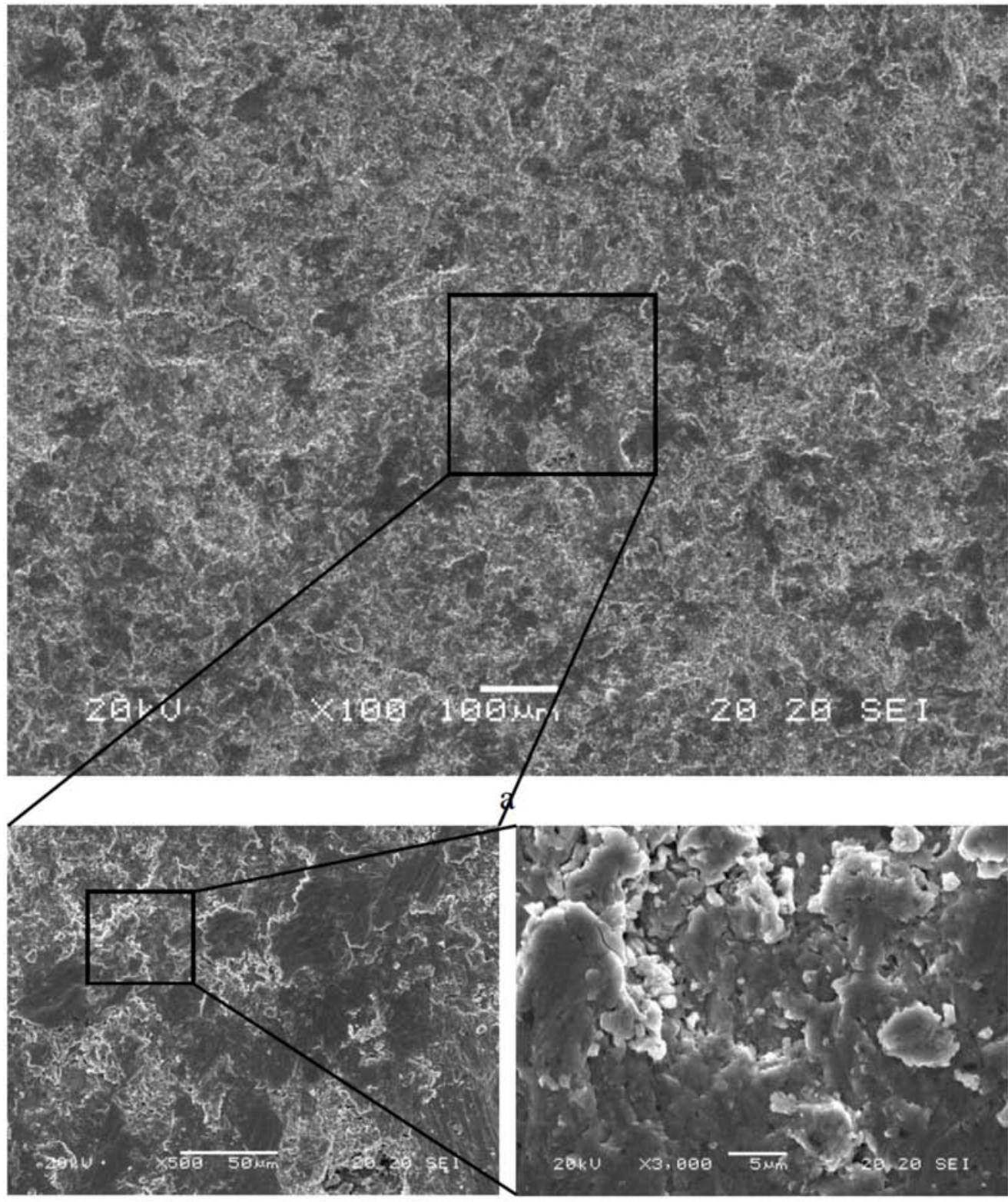

$\mathrm{b}$

c

Figure 10: Machined surface after 120 min milling time. 
Journal of Coating Science and Technology, 2017, Volume 4, No. 3

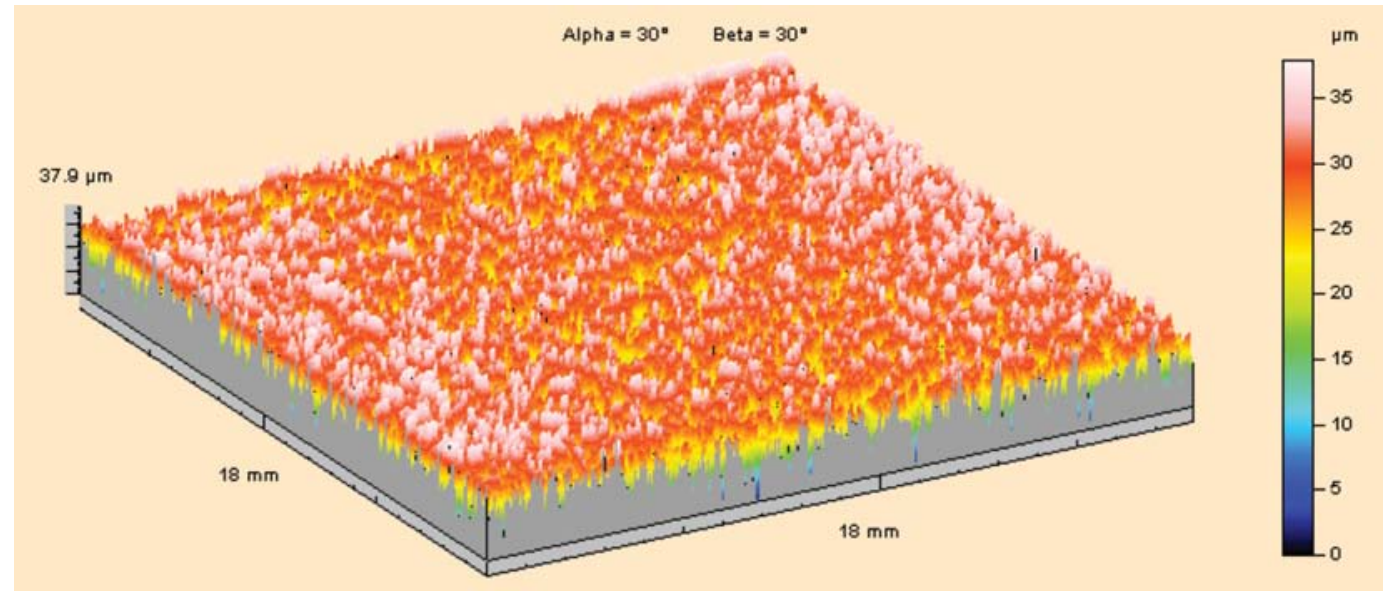

Figure 11: Morphology of machined surface after 180 min milling time.

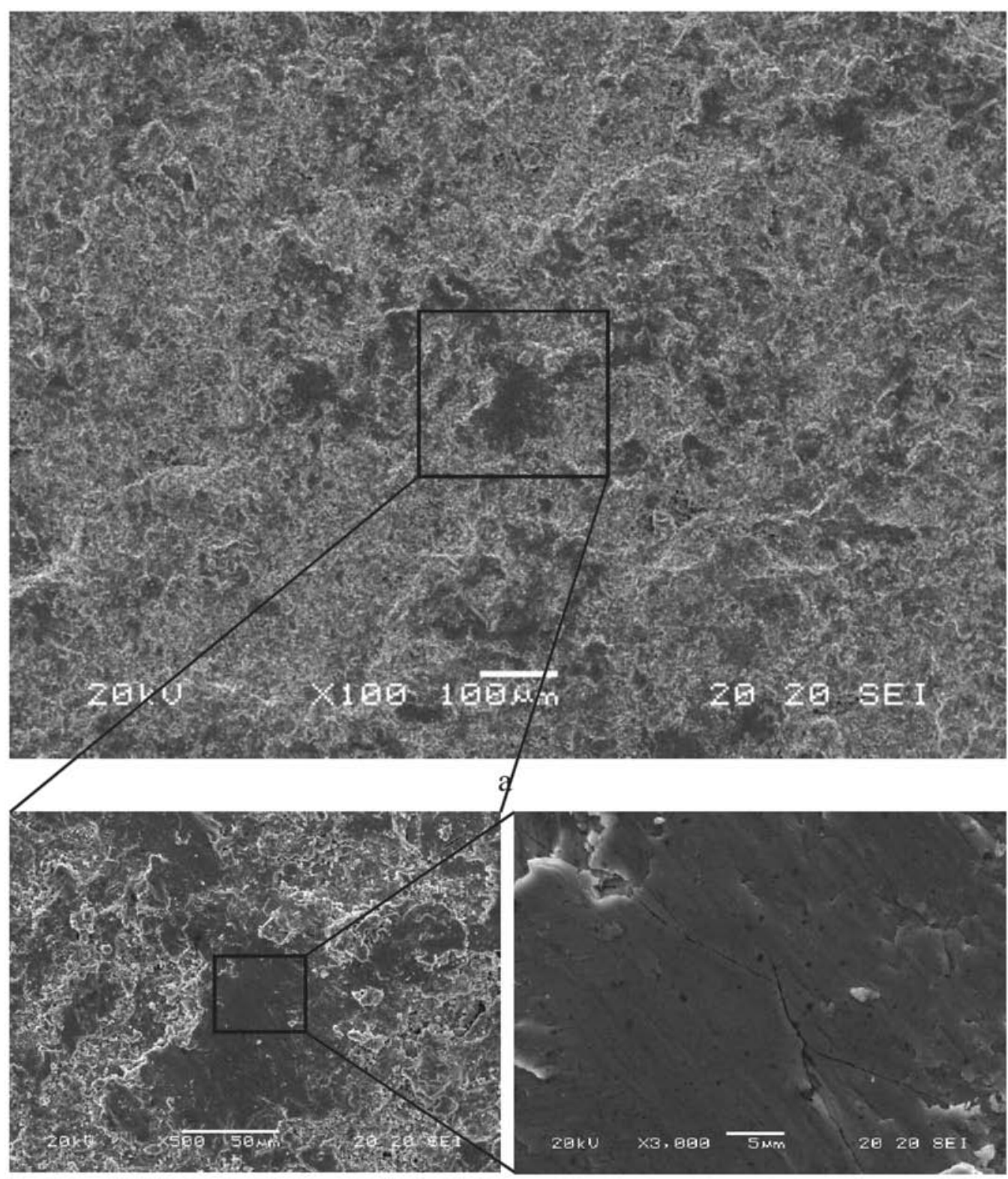

b

$\mathrm{c}$

Figure 12: Machined surface after 180 min milling time. 
When compared with the machined surface of 60 min milling time (Figure 8), the machined surfaces (Figures 9 and 11) of longer milling time give relatively coarser surface. Also, its SEM image (Figures 10a and 12a) and the further magnified counterparts (Figures 10b, 10c, 12b and 12c) show the sign of ridges re-growing bigger, some microparticles aggregating loosely and microcracks scattering on the machined surface. Such surface topography with scattering of micro-aggregation and micro ball-like amorphous features (Figure 10c) implies that there is some level of change of properties of AISI 01 surface. This change is not really anticipated since it is initially expected that the properties of the machined surface topography would be the same as its as-received condition or higher than the initial one.

At longer milling time (i.e. $180 \mathrm{~min}$ ), besides the morphology of the machined surface changes obviously (Figure 11), relatively more severe cracks appear as shown in Figures $12 b$ and 12c, which are likely to change the properties of the initial surface drastically.

\subsection{Roughness of Machined Surface}

Figure 13 shows the relationship between the arithmetic mean surface roughness $R a$ and the milling time. Results indicate that the initial increase in milling time accompanies with the increase in surface roughness until the milling time reaches $60 \mathrm{~min}$ at which the surface roughness is the minimum. Then, further increase in the milling time increases the roughness once again which agrees well with morphology shown in Figures $3 \sim 12$.

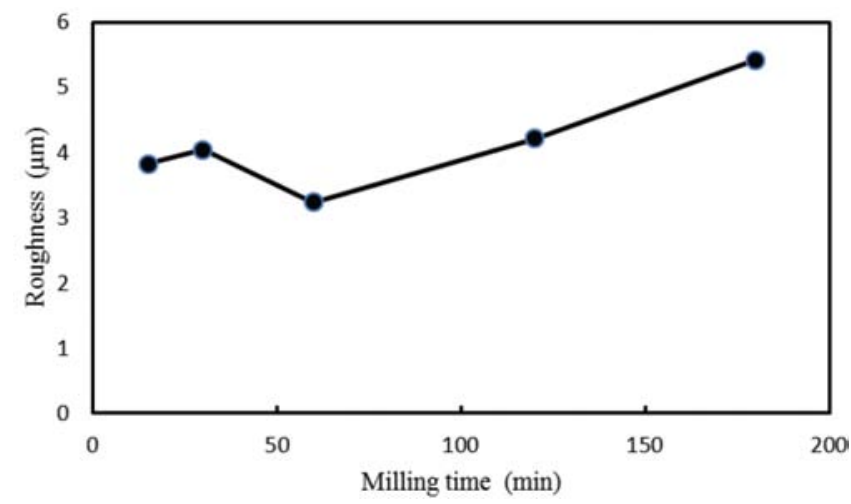

Figure 13: Relationship between $R a$ and milling time.

\subsection{Preliminary Calculation Model}

During the milling process, the mean value of the magnitude of the critical torque $\overline{\tau_{\text {crutical }}}$ can be expressed as:

$\overline{\tau_{\text {crutical }}}=\lambda_{\tau} d_{t}\left[F_{n}+3 f_{\text {adhesion }}\right]$

where $\lambda_{t}$ is a constant in the range $0.5<\lambda_{t}<1, d_{t}$ is the distance parallel to the plane from the center to one of the asperities in contact, $f_{\text {adhesion }}$ is an adhesive force at each contact, $F_{n}$ is the normal body forces. $\overline{\phi_{\text {critical }}}=\lambda_{\phi} \frac{2\left(\frac{3\left|P+f_{\text {adhesion }}\right|}{4 E^{*} \sqrt{R^{*}}}\right)^{\frac{2}{3}}}{3 d_{t}}$

$\overline{\phi_{\text {critical }}}$, the critical angle at which critical torque $\overline{\tau_{\text {crutical }}}$ occurs, $0.63<\lambda_{\varnothing}<1, P$ is the total load, the reduced radius, $R^{*}=\frac{R_{1} R_{2}}{R_{1}+R_{2}}, \quad$ and reduced elastic modulus, $E^{*}=\frac{E_{1} E_{2}}{E_{1}\left(1-v_{2}^{2}\right)+E_{2}\left(1-v_{1}^{2}\right)}$.

$\overline{\tau_{\text {decelerating }}}=-\gamma \omega$

where $\gamma=-2 \xi \eta_{n}\left|d_{t}\right|^{2} n_{2 \pi}$

$\overline{\tau_{\text {decelerating }}}$ is the decelerating torque, $\xi$ is the coefficient ( $\xi<1$, or $\xi \ll 1$ ), $\eta_{n}$ is the damping coefficient, $\omega$ is the angular velocity, $n_{2 \pi}$ is the number of asperities per revolution. $\gamma$ is the adhesive force.

The model consists of expressions for the critical angle and torque at which a ball starts to mill, as well as the rate at which they decelerate. Because of the stochastic nature of surface roughness, it is impossible to accurately reproduce all behavior in a model simple enough to be used in the ball milling phenomena reconstructions. While average milling effect can be accurately replicated, the contact between a real ball and the substrate will not necessarily follow this average due to the details of the geometry. However, in a system of many balls it is often the case that the average behavior dominates. While variations around the average may have a large effect on the motion of each individual ball, the statistical behavior of a system of many balls will not be significantly changed. The model has been derived for contact between a ball and a plane. The contact forces in contacts between two balls will be different, and effects such as interactions between asperities make the system far more complex, but the general principle upon which the model is based still applies. The proposed model can provide an adequate approximation of milling effects in the surface processing when torque is dominated by the largest scale of roughness.

\section{CONCLUSIONS}

The morphology of AISI O1 varies with the different milling time. Increase in milling time simultaneously improves the surface morphology of the substrate. However, too longer milling time will be likely to destroy the surface of substrate which subsequently changes the surface topography and mechanical properties of the steel specimens, which is not really anticipated since it is initially expected that the properties of the machined surface topography would be the same as its as-received condition or higher than the initial 
one. Also, the initial increase in milling time accompanies with the increase in surface roughness until the milling time reaches $60 \mathrm{~min}$ at which the surface roughness is the minimum.

\section{REFERENCES}

[1] Maghsoudi K, Jafari R, Momen G, Farzaneh M. Micro-nanostructured polymer surfaces using injection molding: A review. Materials Today Communications $2017 ; 13$ : 126-143.

https://doi.org/10.1016/i.mtcomm.2017.09.013

[2] Roberts AG, Krauss G, Kennedy LR. Tool Steels. 5th ed., ASM International, Materials Park, Ohio. 1998.

[3] Dehghan-Manshadi A, Bermingham MJ, Dargusch MS, StJohn DH, Qian M. Metal injection moulding of titanium and titanium alloys: Challenges and recent development. Powder Technology 2017; 319: 289-301.

https://doi.org/10.1016/j.powtec.2017.06.053

[4] Ryk G, Kligerman Y, Etson I, Experimental investigation of laser surface texturing for reciprocating automotive components. Tribology Transactions 2002; 45(4): 444-449. https://doi.org/10.1080/10402000208982572

[5] Assarzadeh S, Ghoreishi M. Prediction of root mean square surface roughness in low discharge energy die-sinking EDM process considering the effects of successive discharges and plasma flushing efficiency. Journal of Manufacturing Processes 2017; 30: 502-515. https://doi.org/10.1016/j.jmapro.2017.10.012
Shah Mohammadi M, Ghani M, Komeili M, Crawford B, Milani AS. The effect of manufacturing parameters on the surface roughness of glass fibre reinforced polymer moulds. Composites Part B 2017; 125 39-48.

https://doi.org/10.1016/i.compositesb.2017.05.028

[7] Kelvii Wei Guo, Hon Yuen Tam (2012). Study on Polishing DF2 (AIS O1) Steel by Nd:YAG Laser. Journal of Materials Science Research 2012; 1(1): 54-77.

http://doi.10.5539/imsr.vln1p54

[8] Wei Guo, Meng Hua, Peter Wai-Tat Tse, Albert Chiu Kam Mok Process Parameters Selection for Laser Polishing DF2 (AISI O1) by Nd:YAG Pulsed Laser Using Orthogonal Design. The International Journal of Advanced Manufacturing Technology 2012; 59(9-12): 1009-1023.

https://doi.org/10.1007/s00170-011-3558-1

[9] Kelvii Wei GUO. Effect of Polishing Parameters on Morphology of DF2 (AISI-O1) Steel Surface Polished by Nd:YAG Laser. Surface Engineering 2009; 25 (3): 187-195. https://doi.org/10.1179/026708408X336382

[10] Wei GUO. Effect of Irradiation Parameters on Morphology of Polishing DF2 (AISI-O1) Surface by Nd:YAG Laser. Advance in Materials Science and Engineering (Research Letters in Materials Science) 2007; 3: 5-9. http://doi.10.1155/2007/51316

[11] Lugomer S. Laser Technology-Laser Driven Processes, Prentice Hal Inc. 1990; 419-439.

[12] Steen WM. Laser Material Processing, 3rd ed., Springer-Verlag, London. 2003.

https://doi.org/10.1007/978-1-4471-3752-8 